\title{
Duizeligheid bij ouderen
}

Otto Maarsingh, Jacquelien Dros, François Schellevis, Henk van Weert, Daniëlle van der Windt, Gerben ter Riet, Henriëtte van der Horst

\section{Inleiding}

Duizeligheid komt vaak voor bij ouderen - 30\% van de 65 -plussers ervaart wel eens duizeligheidsklachten en dit loopt op tot $50 \%$ bij mensen boven de 85 jaar. ${ }^{1-3}$ Tien procent van de ouderen bezoekt minimaal één keer per jaar de huisarts in verband met duizeligheid. ${ }^{4}$ Huisartsen vinden de diagnostiek van duizeligheid ingewikkeld: het is een klacht die kan wijzen op tal van oorzaken, variërend van onschuldig tot zeer ernstig. ${ }^{5} \mathrm{Bij} 20$ tot $40 \%$ van de patiënten met duizeligheid blijft de oorzaak onduidelijk, ook na uitgebreid diagnostisch onderzoek. ${ }^{6-8}$

Hoewel de huisarts de klacht duizeligheid vrijwel altijd zelf afhandelt (slechts 3\% van de patiënten met duizeligheid krijgt een verwijzing naar een specialist), ${ }^{9}$ vindt wetenschappelijk onderzoek naar oorzaken van duizeligheid vooral plaats in de tweede of derde lijn. De resultaten van dergelijk onderzoek zijn echter nauwelijks bruikbaar voor de huisarts, omdat het veelal sterk geselecteerde populaties betreft die niet representatief zijn voor de huisartsenpraktijk. Het doel van dit onderzoek was het vaststellen van mogelijke oorzaken van duizeligheid bij ouderen in de huisartsenpraktijk

\section{Samenvatting}

Maarsingh OR, Dros J, Schellevis FG, Van Weert HC, Van der Windt DA, Ter Riet G, Van der Horst HE. Duizeligheid bij ouderen. Huisarts Wet 2010;53(12):674-7.

Doel Het vaststellen van mogelijke oorzaken van duizeligheid bij ouderen in de huisartsenpraktijk.

Methode We voerden bij 417 duizelige patiënten van 65 jaar en ouder een gestandaardiseerd diagnostisch onderzoek uit, bestaande uit 21 tests. Dit diagnostische protocol was gebaseerd op de resultaten van een eerder uitgevoerde Delphi-procedure. Een huisarts, een verpleeghuisarts en een klinisch geriater beoordeelden onafhankelijk van elkaar de resultaten per patiënt, waarna we met behulp van een beslisregel een paneldiagnose construeerden bestaande uit 'hoofdoorzaak duizeligheid' en 'bijdragende oorzaak/oorzaken duizeligheid'

Resultaten Volgens het panel was de meest voorkomende hoofdoorzaak van duizeligheid een cardiovasculaire aandoening (57\% van de patiënten), gevolgd door een vestibulaire aandoening (14\%) en een psychiatrische aandoening (10\%). De meest voorkomende bijdragende oorzaak was bijwerking van medicatie (23\%). Bij 62\% van de patiënten was er sprake van twee of meer bijdragende oorzaken van duizeligheid.

Conclusie Duizeligheid bij ouderen lijkt in de huisartsenpraktijk

\section{Methode \\ Setting en onderzoekspopulatie}

De onderzoekspopulatie bestond uit patiënten van 65 jaar of ouder die hun huisarts consulteerden in verband met minimaal twee weken bestaande duizeligheid. Huisartsen uit 24 praktijken in de provincies Noord-Holland en Utrecht verwezen in de periode van juli 2006 tot en met januari 2008 patiënten naar ons door. Aanvullend zochten wij maandelijks in het HIS van alle deelnemende praktijken om eventueel niet aangemelde patiënten te identificeren en alsnog uit te nodigen voor ons onderzoek. Het begrip duizeligheid omvatte de volgende contactredenen: duizelig, een draaierig of zweverig gevoel, onvast/wankel ter been of valneiging en gevoel van flauwte, licht in het hoofd of zwart voor de ogen. Exclusiecriteria waren onvoldoende Nederlandse of Engelse spreekvaardigheid, ernstige cognitieve beperkingen, blindheid (gecorrigeerde visus beste oog < 3/60), doofheid (verbale communicatie onmogelijk) of rolstoelafhankelijkheid

\section{Diagnostisch onderzoek}

Een arts-onderzoeker verrichtte bij alle patiënten een gestandaardiseerd diagnostisch onderzoek bestaande uit 21 tests (duur

vooral cardiovasculair (en niet vestibulair) bepaald. Dat is in tegenspraak met eerder gepubliceerd onderzoek. Bij een kwart van de ouderen draagt medicatie mogelijk bij aan de duizeligheid, hetgeen veel hoger is dan men tot op heden aannam.

VUmc, EMGO Instituut, afdeling Huisartsgeneeskunde, Van der Boechorststraat 7, 1081 BT Amsterdam: O.R. Maarsingh, huisarts-onderzoeker; prof dr. F.G. Schellevis, hoogleraar huisartsgeneeskunde; prof.dr. H.E. van der Horst, hoogleraar huisartsgeneeskunde. AMC, afdeling Huisartsgeneeskunde, Amsterdam: J. Dros, huisarts-onderzoeker; dr. G. Ter Riet, arts klinisch epidemioloog, universitair hoofddocent; dr. H.C.P.M. van Weert huisarts, universitair hoofddocent. Nederlands Instituut voor Onderzoek van de Gezondheidszorg (NIVEL): prof.dr. F.G. Schellevis, hoofd onderzoeksafdeling. Keele University, Engeland: prof.dr. D.A.W.N van der Windt professor in primary care epidemiology.

Correspondentie: o.maarsingh@vumc.nl

Mogelijke belangenverstrengeling: niets aangegeven

Dit artikel is een bewerkte vertaling van: Maarsingh OR, Dros J, Schellevis FG, Van Weert HC, Van der Windt DA, Ter Riet G, et al. Causes of persistent dizziness in elderly patients in primary care: a diagnostic study based on panel diagnosis. Ann Fam Med 2010;8:196-205. Publicatie gebeurt met toestemming van de uitgever 
Wat is bekend?

- Duizeligheid komt veel voor bij ouderen in de huisartsenpraktijk.

- Duizeligheid bij ouderen heeft vaak meer dan één oorzaak.

Wat is nieuw?

Duizeligheid bij ouderen in de huisartsenpraktijk is waarschijnlijk vooral cardiovasculair (en niet vestibulair) van origine.

- Bij één op de vier duizelige ouderen levert medicatie mogelijk een bijdrage aan de duizeligheid

ongeveer 75 minuten), gebaseerd op de resultaten van een eerder uitgevoerde Delphi-procedure. ${ }^{10}$ Het diagnostisch onderzoek vond plaats in een van de deelnemende praktijken of thuis indien een patiënt niet in staat was de praktijk te bezoeken. Het onderzoek bestond uit een uitgebreide anamnese waarbij de arts-onderzoeker onder andere vroeg naar de kenmerken van de duizeligheid (aard/ontstaan/duur/frequentie/uitlokkende omstandigheden/begeleidende symptomen), het gebruik van valrisicoverhogende medicatie ${ }^{11}$ en het gebruik van hulpmiddelen. De invloed van de duizeligheidsklachten op het dagelijks leven brachten we in kaart met behulp van de Dizziness Handicap Inventory (DHI). ${ }^{12}$ Het tweede deel van het onderzoek bestond uit lichamelijk en aanvullend onderzoek van het cardiovasculair systeem (pols, bloeddruk, orthostatische hypotensietest, auscultatie van het hart; elektrocardiogram en eventrecorder verrichtten we alleen op indicatie, zie de oorspronkelijke publicatie), ${ }^{13-15}$ het houdings- en bewegingsapparaat (orthopedische screening van onderste extremiteiten, koorddansersgang en timed 'up and go' test), ${ }^{16,17}$ en het vestibulair systeem (otoscopie, kiepproef van Dix-Hallpike en audiogram). ${ }^{18-21}$ Aanvullend deden we neurologisch onderzoek (peesreflexen en Semmes-Weinstein Monofilament Test), ${ }^{22-24}$ psychiatrisch onderzoek (met de Patient Health Questionnaire (PHQ)), 25,26 laboratoriumonderzoek (hemoglobine en niet nuchtere bloedsuiker) en onderzoek van de visus.

\section{Paneldiagnose}

Omdat aan de klacht duizeligheid vaak meer dan een aandoening ten grondslag ligt ${ }^{6,27}$ en voor de meeste van deze aandoeningen een gouden standaard ontbreekt, ${ }^{28}$ zullen de diagnostische voorkeuren van één enkele beoordelaar de interpretatie van testresultaten bij onderzoek naar duizeligheid gemakkelijk kunnen beïnvloeden. ${ }^{6}$ We hebben er daarom voor gekozen de resultaten van iedere patiënt te laten beoordelen door drie onafhankelijke beoordelaars (huisarts, verpleeghuisarts en klinisch geriater). De beoordelaars kregen de opdracht om per patiënt op een scoreformulier aan te geven wat de relatieve bijdrage (0-100\%) was van negen categorieën van mogelijke oorzaken van duizeligheid:

- bijwerking van medicatie;

- cardiovasculaire aandoeningen (inclusief cerebrovasculaire aandoeningen);

- aandoeningen van het houdings- en bewegingsapparaat;

- metabole aandoeningen;
- neurologische aandoeningen (exclusief cerebrovasculaire aandoeningen);

- psychiatrische aandoeningen;

- vestibulaire aandoeningen;

- visusaandoeningen;

- overige oorzaken. 5,29,30

We vroegen de beoordelaars tevens bij iedere patiënt een beschrijvende diagnose te vermelden. Vervolgens gebruikten we deze informatie om met behulp van een beslisregel (zie de oorspronkelijke publicatie) per patiënt een paneldiagnose te construeren, bestaande uit 'hoofdoorzaak duizeligheid' en 'bijdragende oorzaak/oorzaken duizeligheid'

\section{Resultaten}

Gedurende een periode van 19 maanden sloten we 417 duizelige ouderen in. We excludeerden 31 aangemelde patiënten vanwege het verdwijnen van de duizeligheid $(n=10)$, het alsnog niet voldoen aan de inclusiecriteria $(n=4)$, de fysieke onmogelijkheid om deel te nemen aan het onderzoek $(n=2)$ en de weigering om deel te nemen $(n=15)$.

De gemiddelde leeftijd van onze populatie was 79 jaar (spreiding 65-95), 74\% van de patiënten was vrouw. De patiënten gebruikten gemiddeld 4 verschillende medicijnen; 33\% gebruikte 6 of meer medicijnen en 37\% gebruikte 3 of meer valrisicoverhogende medicijnen. Vaak omschreven patiënten hun duizeligheid als 'onvast/ wankel ter been' (69\%), 'verstoorde balans' (67\%), 'licht in het hoofd' (59\%) en 'draaierigheid' (55\%). Bij een meerderheid van de patiënten $(69 \%)$ bestond de duizeligheid ten minste 6 maanden. Belangrijkste uitlokkende factoren waren omhoog komen vanuit liggende of zittende positie (70\%), voorover buigen (62\%) en draaien van het hoofd (53\%). Belangrijkste begeleidende klachten waren (bijna) vallen (50\%), problemen met lopen (44\%) en misselijkheid (27\%). Frequent afwijkende bevindingen bij lichamelijk en aanvullend onderzoek waren een afwijkende Semmes-Weinstein Monofilament Test (50\%), afwijkende audiometrie voor beide oren (48\%), een hoge systolische bloeddruk ( $\geq 160 \mathrm{mmHg}$; 48\%), gestoorde stabiliteit in rust (46\%), de aanwezigheid van minimaal één psychiatrische diagnose volgens de $\mathrm{PHO}$ (42\%), een gestoorde visus (ODS $\leq 0,5 ; 29 \%$ ) en orthostatische hypotensie (24\%). Vijf keer was er sprake van afwijkende bevindingen waarvoor we direct (diagnostisch dan wel therapeutisch) handelen noodzakelijk achtten: ernstige anemie $(n=3)$ en een derdegraads-AV-blok $(n=2)$.

Het panel oordeelde op basis van de testresultaten dat een cardiovasculaire aandoening bij 57\% van de patiënten de meest waarschijnlijke hoofdoorzaak was. Bij 14\% van de patiënten was dat een vestibulaire aandoening en bij 10\% een psychiatrische aandoening (figuur). Duizeligheid als bijwerking van medicatie was volgens het panel de meest voorkomende bijdragende oorzaak (23\%). Bij 62\% van de patiënten was er sprake van twee of meer bijdragende oorzaken van duizeligheid. Bij $8 \%$ van de patiënten was het niet mogelijk een paneldiagnose te construeren, omdat er onvoldoende overeen stemming tussen de beoordelaars was of omdat de beoordelaars de oorzaak van de duizeligheid allen als 'onduidelijk' bestempelden. 
Figuur Oorzaken van duizeligheid bij ouderen in de huisartsenpraktijk (paneldiagnose)

1. Bijwerking medicatie

2. Cardiovasculaire aandoeningen (incl. cerebrovasc. aand.)

3. Aandoeningen van het $\mathrm{H} \& \mathrm{~B}$ apparaat

4. Metabole aandoeningen

5. Neurologische aandoeningen (excl. cerebrovasc. aand.)

6. Psychiatrische aandoeningen

7. Vestibulaire aandoeningen

8. Aandoeningen visus

9. Overige aandoeningen

Onduidelijke consensus
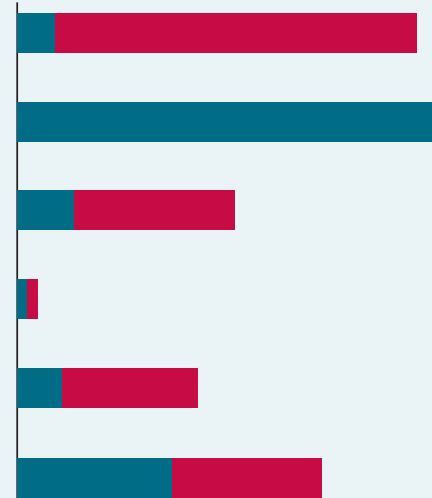

Hoofdoorzaak duizeligheid

Bijdragende oorzaak duizeligheid

\begin{tabular}{|c|c|c|c|c|c|c|c|c|}
\hline & $T$ & $T$ & $T$ & $T$ & $T$ & $T$ & $T$ & $T$ \\
\hline \multirow[t]{2}{*}{0} & 10 & 20 & 30 & 40 & 50 & 60 & 70 & 80 \\
\hline & & & & $\%$ & & & & \\
\hline
\end{tabular}

\section{Beschouwing}

Hoewel patiënten de huisarts vaak consulteren vanwege duizeligheid en hij/zij dit bijna altijd zelf afhandelt, ${ }^{4,9}$ is er tot op heden weinig onderzoek gedaan naar oorzaken van duizeligheid in de huisartsenpraktijk. In ons onderzoek was een cardiovasculaire aandoening volgens het panel de meest voorkomende oorzaak van duizeligheid bij ouderen. Dit lijkt in tegenspraak met eerder gepubliceerd onderzoek, waaruit bleek dat vestibulaire aandoeningen de meest voorkomende oorzaak van duizeligheid zijn. Veel onderzoeken zijn echter niet representatief voor de huisartsenpraktijk, omdat er sprake is van een sterk geselecteerde populatie (patiënten op de spoedeisende hulp of patiënten verwezen naar een medisch specialist). ${ }^{8,31-39}$

Het medicijngebruik bij onze onderzoekspopulatie was aanzienlijk (33\% van de patiënten gebruikte 6 of meer medicijnen). Volgens het panel was bijwerking van medicatie een oorzaak van duizeligheid bij 1 op de 4 duizelige ouderen, hetgeen aanzienlijk frequenter is dan eerdere publicaties vermelden (1-9\%).8,31,33,38,40 Dit verschil is slechts gedeeltelijk te verklaren door de relatief hoge leeftijd van onze onderzoekspopulatie. Mogelijk heeft men de bijdrage van medicatie bij eerder onderzoek onderschat, aangezien veel onderzoekers slechts een gedeelte van de relevante medicatie in kaart brachten.

Bestudering van de beschikbare literatuur laat tevens zien dat de gerapporteerde verdeling van oorzaken van duizeligheid sterk uiteenloopt, waarbij opvalt dat onderzoekers geneigd zijn vooral datgene te diagnosticeren dat hun interesse heeft. ${ }^{5}$ Philip Sloane refereerde in dit verband aan 'the blind men and the elephant', een parabel uit het oude India die illustreert dat waarneming sterk afhankelijk is van het perspectief van de waarnemer. ${ }^{41}$ Met ons onderzoek hebben we geprobeerd de invloed van een dergelijk fenomeen te reduceren door gebruik te maken van de mening van 16 experts uit 8 verschillende medische disciplines (cardiologie, geriatrie, huisartsgeneeskunde, interne geneeskunde, kno, neurologie, revalidatiegeneeskunde en verpleeghuisgeneeskunde) voor de selectie van diagnostische tests ${ }^{10}$ en door de testresultaten vervolgens te laten beoordelen door clinici afkomstig uit drie verschillende medische disciplines (geriatrie, huisartsgeneeskunde en verpleeghuisgeneeskunde), alle drie met een algemeen karakter. We kunnen echter niet uitsluiten dat het fenomeen van 'the blind men' ook in ons onderzoek is opgetreden, zowel op het niveau van de selectie van tests (dat wil zeggen dat we sommige diagnostische tests mogelijk ten onrechte wel/niet geselecteerd hebben als gevolg van persoonlijke voorkeuren van de experts tijdens de Delphi-procedure), als op het niveau van de interpretatie van tests (dat wil zeggen dat we sommige categorieën van oorzaken van duizeligheid hebben overschat/onderschat als gevolg van voorkeuren van clinici tijdens het paneloordeel).

\section{Conclusie}

Bij meer dan 50\% van de duizelige ouderen in de huisartsenpraktijk was een cardiovasculaire aandoening de meest waarschijnlijke hoofdoorzaak. Wij adviseren huisartsen om bij de diagnostiek van duizeligheid bij ouderen altijd voldoende aandacht te besteden aan mogelijk onderliggende cardiovasculaire aandoeningen. Omdat medicatie waarschijnlijk geregeld bijdraagt aan duizelig- 
heid bij ouderen, raden wij huisartsen tevens aan om bij ouderen met duizeligheid altijd de medicatiestatus te beoordelen (het bijwerkingenprofiel van actuele medicatie, eventuele interacties, eventuele dubbelmedicatie, enzovoort).

\section{Literatuur}

1 Colledge NR, Wilson JA, Macintyre CC, MacLennan WJ. The prevalence and characteristics of dizziness in an elderly community. Age Ageing 1994;23:117-20.

2 Jonsson R, Sixt E, Landahl S, Rosenhall U. Prevalence of dizziness and vertigo in an urban elderly population. J Vestib Res 2004;14:4752.

3 Tinetti ME, Williams CS, Gill TM. Dizziness among older adults: a possible geriatric syndrome. Ann Intern Med 2000;132:337-44.

4 Maarsingh OR, Dros J, Schellevis FG, Van Weert HC, Bindels PJ, Van der Horst HE. Dizziness reported by elderly patients in family practice: prevalence, incidence, and clinical characteristics. BMC Fam Pract 2010;11:2.

5 Sloane PD, Coeytaux RR, Beck RS, Dallara J. Dizziness: state of the science. Ann Intern Med 2001;134:823-32.

6 Kroenke K, Lucas CA, Rosenberg ML, Scherokman B, Herbers JE Jr, Wehrle PA, et al. Causes of persistent dizziness. A prospective study of 100 patients in ambulatory care. Ann Intern Med 1992;117:898-904.

7 Lawson J, Fitzgerald J, Birchall J, Aldren CP, Kenny RA. Diagnosis of geriatric patients with severe dizziness. J Am Geriatr Soc 1999;47:12-7.

8 Madlon-Kay DJ. Evaluation and outcome of the dizzy patient. J Fam Pract 1985;21:109-13.

9 Okkes IM, Oskam SK, Lamberts H. Van klacht naar diagnose. Episodegegevens uit de huisartspraktijk. Bussum: Coutinho, 1998.

10 Maarsingh OR, Dros J, Van Weert HC, Schellevis FG, Bindels PJ, Van der Horst HE. Development of a diagnostic protocol for dizziness in elderly patients in general practice: a Delphi procedure. BMC Fam Pract 2009;10:12.

11 Van der Velde N, Stricker BH, Pols HA, Van der Cammen TJ. Risk of falls after withdrawal of fall-risk-increasing drugs: a prospective cohort study. Br J Clin Pharmacol 2007;63:232-7.

12 Jacobson GP, Newman CW. The development of the Dizziness Handicap Inventory. Arch Otolaryngol Head Neck Surg 1990;1 16:424-7.

13 Atkins D, Hanusa B, Sefcik T, Kapoor W. Syncope and orthostatic hypotension. Am J Med 1991;91:179-85.

14 Brignole M, Alboni P, Benditt DG, Bergfeldt L, Blanc JJ, Bloch Thomsen PE, et al. Guidelines on management (diagnosis and treatment) of syncope. Update 2004. Europace 2004;6:467-537.

15 Hoefman E, Van Weert HC, Boer KR, Reitsma J, Koster RW, Bindels PJ. Optimal duration of event recording for diagnosis of arrhythmias in patients with palpitations and light-headedness in the general practice. Fam Pract 2007;24:11-3.

16 Brinkman DMC, Kuipers-Upmeijer J, Oosterhuis HJGH. Kwantificering en evaluatie van 5 neurologische evenwichtstests bij proefpersonen en patiënten. Ned Tijdschr Geneeskd 1996;140:2176-80.

17 Podsiadlo D, Richardson S. The timed 'Up and Go': A test of basic functional mobility for frail elderly persons. J Am Geriatr Soc 1991;39:142-8

18 Dix MR, Hallpike CS. The pathology, symptomatology and diagnosis of certain common disorders of the vestibular system. Ann Otol Rhinol Laryngol 1952;61:987-1016.
19 Eekhof JAH, Ek JW, Van Weert HCPM, Spies TH, Hufman PW, Hoftijzer NP. NHG-Standaard Slechthorendheid. Huisarts Wet 1997;40:70-8

20 Fife TD, Tusa RJ, Furman JM, Zee DS, Frohman E, Baloh RW, et al. Assessment: vestibular testing techniques in adults and children: report of the Therapeutics and Technology Assessment Subcommittee of the American Academy of Neurology. Neurology 2000;55:1431-41.

21 Furman JM, Cass SP. Benign paroxysmal positional vertigo. N Engl J Med 1999;341:1590-6.

22 Boulton J, Vinik A, Arezzo J, Zee DS, Frohman E, Baloh RW, et al. Diabetic Neuropathies, a statement by the American Diabetes Association. Diabetes Care 2005;28:956-62.

23 NHS National Institute for Clinical Excellence (NICE). Type 2 diabetes Prevention and management of foot problems, Clinical Guideline 10. Londen: National Institute for Clinical Excellence, 2004.

24 Singh N, Armstrong DG, Lipsky BA. Preventing foot ulcers in patients with diabetes. JAMA 2005;293:217-28

25 Persoons P, Luyckx K, Desloovere C, Vandenberghe J, Fischler B. Anxiety and mood disorders in otorhinolaryngology outpatients presenting with dizziness: Validation of the self-administered PRIME-MD Patient Health Questionnaire and epidemiology. Gen Hosp Psychiatry 2003;25:316-23.

26 Spitzer RL, Williams JB, Kroenke K, Linzer M, deGruy FV 3rd, Hahn $\mathrm{SR}$, et al. Utility of a new procedure for diagnosing mental disorders in primary care. The PRIME-MD 1000 study. JAMA 1994;272:1749-56.

27 Colledge NR, Barr-Hamilton RM, Lewis SJ, Sellar RJ, Wilson JA. Evaluation of investigations to diagnose the cause of dizziness in elderly people: a community based controlled study. BMJ 1996;313:788-92.

28 Dros J, Maarsingh OR, Van der Horst HE, Bindels PJ, Ter Riet G, Van Weert HC. Dizziness in primary care: a systematic review of diagnostic tests. CMAJ 2010;182:E621-E631.

29 Baloh RW. Vertigo. Lancet 1998;352:1841-6.

30 Hoffman RM, Einstadter D, Kroenke K. Evaluating dizziness. Am I Med 1999;107:468-78.

31 Davis LE. Dizziness in elderly men. J Am Geriatr Soc 1994;42:1 184-8.

32 Drachman DA, Hart CW. An approach to the dizzy patient. Neurology 1972;22:323-34

33 Herr RD, Zun L, Mathews JJ. A directed approach to the dizzy patient Ann Emerg Med 1989;18:664-72.

34 Katsarkas A. Dizziness in aging: a retrospective study of 1194 cases. Otolaryngol Head Neck Surg 1994;110:296-301.

35 Katsarkas A. Dizziness in aging: the clinical experience. Geriatrics 2008;63:18-20.

36 Nedzelski JM, Barber HO, Mcllmoyl L. Diagnoses in a dizziness unit. J Otolaryngol 1986;15:101-4

37 Newman-Toker DE, Hsieh YH, Camargo CA, Jr., Pelletier AJ, Butchy GT, Edlow IA. Spectrum of dizziness visits to US emergency departments: cross-sectional analysis from a nationally representative sample. Mayo Clin Proc 2008;83:765-75

38 Sloane PD, Baloh RW. Persistent dizziness in geriatric patients. J Am Geriatr Soc 1989:37:1031-8.

39 Uneri A, Polat S. Vertigo, dizziness and imbalance in the elderly. J Laryngol Otol 2008;122:466-9.

40 Sloane PD, Dallara J, Roach C, Bailey KE, Mitchell M, McNutt R. Management of dizziness in primary care. J Am Board Fam Pract 1994; 7:1-8

41 Sloane PD, Dallara J. Clinical research and geriatric dizziness: the blind men and the elephant. J Am Geriatr Soc 1999;47:113-4. 